\title{
Endoscopic "stenting bridge" to treat combined gastric perforation, jejunal stump dehiscence, and biliodigestive anastomosis leak after duodenopancreatectomy followed by pancreatic totalization
}

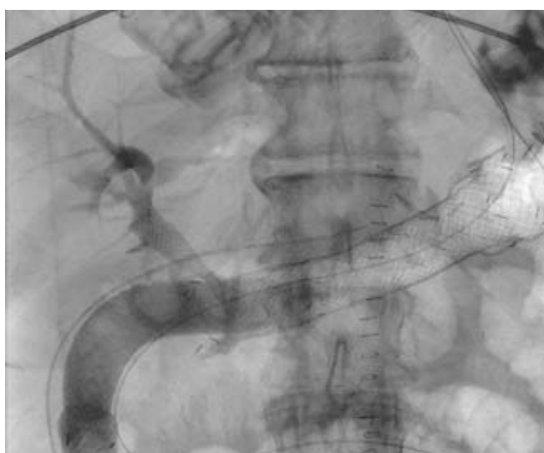

Fig. 1 Fluoroscopic view at the end of the endoscopic procedure, showing the enteral stents with the imbricated biliary stent and the $18-\mathrm{Fr}$ suction tube inside.

Duodenopancreatectomy is burdened by a high rate of postoperative complications including anastomotic dehiscence. Although repeat surgery is considered the gold standard treatment in these settings $[1,2]$, it has high morbidity and mortality rates $[3,4]$; thus, alternative treatments (i.e. endotherapy) have been investigated to improve clinical outcomes.

A 63-year-old man underwent WhippleChild operation for major papilla adenocarcinoma ( $\mathrm{TT} 2 \mathrm{~N} 2)$. Surgery was complicated by anastomotic dehiscence of pancreaticojejunostomy, which was treated by pancreatic totalization. Subsequently, the patient developed severe sepsis associated with high output of enteral fluids from abdominal drains $(600 \mathrm{~mL}$ ) day). The patient was considered unfit for surgery because of septic status and poor general condition.

An endoscopy was performed to assess the type and severity of complications. Endoscopy revealed a large leak on the lesser curvature of the gastric stump through which it was possible to access the intra/retroperitoneal cavity and to observe complete dehiscence of the jejunal stump ( $\triangleright$ Video 1 ). Exploiting this large and complex dehiscence, we tried
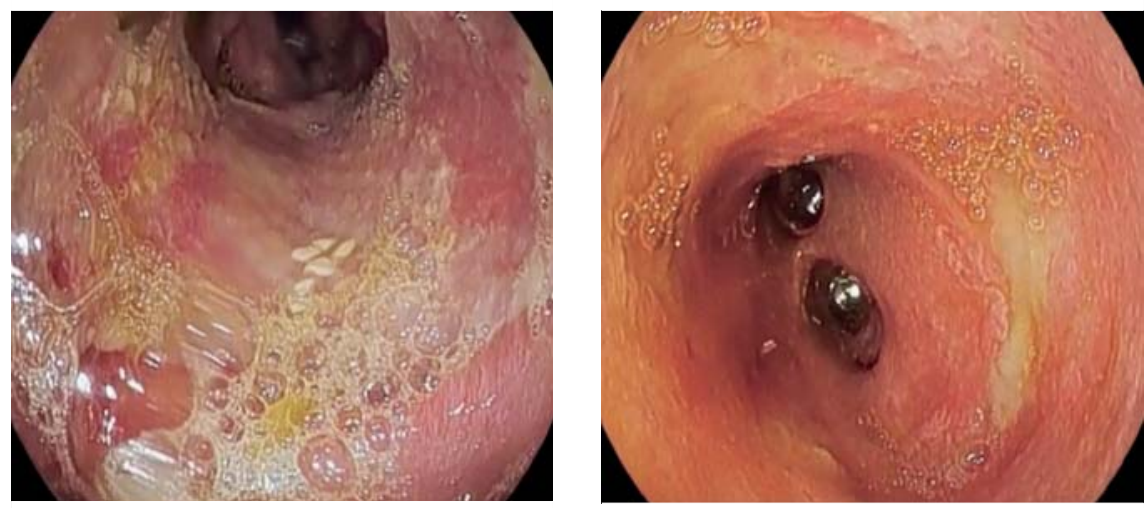

Fig. 2 Endoscopic view of the results after stent removal, showing the fibrotic tissue connecting the gastric stump to the

- Fig. 3 Endoscopic view of the biliodigestive anastomosis after stent removal.

Video 1 Endoscopic treatment of combined gastric perforation, jejunal stump, and biliojejunal anastomotic dehiscence after duodenopancreatectomy and pancreatic totalization.

endoscopically to restore intestinal continuity. A fully covered self-expandable metal stent (fc-SEMS), $24 \mathrm{~mm} \times 10 \mathrm{~cm}$ (EuroMedical Corp., Prague, Czech Republic) was placed over the wire through the necrotic cavity to restore the connection between the gastric cavity and the biliary jejunal loop. Biliodigestive anastomotic leak was also confirmed during endoscopy; thus, we decided to also perform double stenting to repair the leak. A second enteral fc-SEMS $20 \mathrm{~mm} \times 10 \mathrm{~cm}$ (EuroMedical Corp.) was placed into the jejunal loop, through the previously placed enteral stent. A $10 \mathrm{~mm} \times 4 \mathrm{~cm}$ fc-SEMS (WallFlex; Boston Scientific, Marlborough, Massachusetts, USA) was then inserted through the meshes of 
the second enteral stent, into the main bile duct. At the end of the procedure, an $18-\mathrm{Fr}$ nasojejunal suction tube was positioned inside the two enteral stents and held in continuous aspiration $(-75 \mathrm{mmHg})$ ( Fig. 1 ).

A second biliary $16 \mathrm{~mm} \times 2 \mathrm{~cm}$ fc-SEMS (Nagi-S; Taewoong Medical, Gyeonggido, South Korea) was placed 3 days later because of displacement of the previous biliary SEMS (possibly due to proximal traction of the enteral SEMSs after full expansion).

The continuous aspiration was stopped after 15 days because the surgical drainage output became null. The patient was discharged after 3 months of hospitalization (and 4 weeks after the endoscopic procedure).

All stents were removed 8 weeks after endoscopy. Fluoroscopy showed no residual leaks. At endoscopy, the gastric stump appeared to be connected to the jejunal loop by a fibrotic tunnel ( $>$ Fig. 2) and the biliodigestive anastomosis was regular (> Fig. 3 ).

Endoscopy_UCTN_Code_TTT_1AO_2AI

\section{Competing interests}

The authors declare that they have no conflict of interest.
The authors

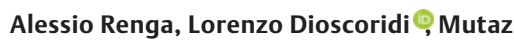
Massad, Marcello Cintolo, Giulia Bonato, Francesca Aprile, Massimiliano Mutignani Digestive Endoscopy Unit, ASST Niguarda, Milan, Italy

\section{Corresponding author}

\section{Lorenzo Dioscoridi, MD, PhD}

Digestive Endoscopy Unit, ASST Niguarda, Piazza dell'Ospedale Maggiore 1, 20162, Milan, Italy

dioscoridi.lorenzo@virgilio.it

\section{References}

[1] Babu B, Finch J. Current status in the multidisciplinary management of duodenal fistula. Surgeon 2013; 11: 158-164

[2] Fang JF, Chen RJ, Lin BC. Surgical treatment and outcome after delayed diagnosis of blunt duodenal injury. Eur J Surg 1999; 165 : 133-189

[3] Cozzaglio L, Coladonato M, Biffi R et al. Duodenal fistula after elective gastrectomy for malignant disease: an Italian retrospective multicenter study. J Gastrointest Surg 2010; 14: 805

[4] Hollington P, Mawdsley J, Lim W et al. An 11-year experience of enterocutaneous fistula. Br J Surg 2004; 91: 1646
Bibliography

Endoscopy 2022; 54: E443-E444

DOI $10.1055 / \mathrm{a}-1625-2892$

ISSN 0013-726X

published online 17.9.2021

(c) 2021. Thieme. All rights reserved.

Georg Thieme Verlag KG, Rüdigerstraße 14,

70469 Stuttgart, Germany

\section{ENDOSCOPY E-VIDEOS \\ https://eref.thieme.de/e-videos}

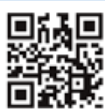

Endoscopy E-Videos is an open access online section, reporting on interesting cases

and new techniques in gastroenterological endoscopy. All papers include a high quality video and all contributions are freely accessible online. Processing charges apply (currently EUR 375), discounts and wavers acc. to HINARI are available.

This section has its own submission website at https://mc.manuscriptcentral.com/e-videos 